\title{
CAMINHOS POSSÍVEIS NA PESQUISA EM LÍNGUA PORTUGUESA E SUAS LITERATURAS
}

POSSIBLE WAYS IN RESEARCH IN PORTUGUESE LANGUAGE \& ITS LITERATURES

Maged Talaat Mohamed Ahmed Elgebaly

Investigador do Instituto de Literatura Comparada Margarida Losa da Universidade do Porto/ Bolseiro do Instituto Camões. Professor coordenador do Departamento de Língua Portuguesa da Aswan University. 
Resumo: Neste artigo, busca-se revisar os possíveis caminhos na pesquisa luso-brasileira em língua portuguesa e suas literaturas entre os anos de 1970 até o ano de 2020. Partimos nesse recorte da nossa experiência no ensino e na pesquisa em língua portuguesa no contexto egípcio, ressaltando os sentidos linguístico, literário, tradutório, turístico e educativo da linguagem humana em três eixos: o significar, o comunicar e o interagir. A complexidade dessas experiências em língua portuguesa ganha relevância por meio da interdisciplinaridade e da interculturalidade, proporcionando um diálogo entre os diversos grupos culturais que se encontram nessa língua, sejam nos estudos e pesquisas do campo ou no aprendizado da língua.

Palavras-chave: língua portuguesa, literatura, tradução, turismo, educação. 
Abstract: In this article, we revise possible paths in Luso-Brazilian language and its literatures research between the decade of 1970 until the year of 2020 . We start from section of the meanings of linguistic, literary, translational, touristic and educational experiences of human language: signifying, communicating and interacting. The complexity of these experiences in Portuguese Language takes on meaning through interdisciplinary and interculturality, providing a dialogue between various cultural groups that meet through that language, or in studies and researches in this field or in a language learning.

Keywords: Portuguese language, literature, translation, tourism, education. 


\section{Introdução}

A língua portuguesa e suas literaturas aqui são tomadas como objeto de conhecimento e pesquisa bem diversificados na área de Letras. A minha trajetória como professor e pesquisador de língua portuguesa e suas literaturas no Egito me proporcionou esboçar essa revisão do estado da arte da área. Partimos dos anos de 1970 até as produções mais atuais e, dentro dos limites de um artigo, farei uma leitura da situação da língua portuguesa e suas literaturas, com recortes necessários que envolvem as tendências com as quais mais de perto entrei em contato durante minha vida acadêmica e aquelas que possivelmente serão desenvolvidas no âmbito das universidades no Egito.

A análise vai partir de alguns focos temáticos divididos em três: o campo da linguística, o da literatura e o da tradução. No que tange à linguística, apresentamos os focos fonético-ortográfico, gramatical e sintático; a análise do discurso, a linguística textual; a pragmática da língua e o português como língua adicional. Quanto ao estudo das literaturas de língua portuguesa confrontamo-nos com vários modos de intervenção crítica como a análise semiótica, as abordagens filosóficas, sociológicas e históricas da poesia e da prosa, os estudos das narrativas e do drama. Na tradução, de acordo com Williams \& Chesterman (2002), pesquisam-se três processos: a hermenêutica 
do tradutor, a retórica do tradutor e a sociologia do tradutor.

Todos esses aspectos foram de certo modo contemplados no recorte desse panorama do estado da arte da língua portuguesa e suas literaturas. 0 intuito era abarcar a maior parte das pesquisas na área e os campos de análise associados, tendo, porém como pressuposto a inexequível tarefa de atingir a totalidade dos trabalhos e a expectativa de futuras pesquisas sobre a língua portuguesa e suas literaturas.

\section{O estado da arte da Língua Portuguesa e suas literaturas}

Chama-se estado da arte ao mapeamento do percurso de pesquisas em um determinado campo de conhecimento e o modo como são abordados os diversos temas e as perspectivas para os seus futuros trabalhos. Nesse sentido, para elaborar um estado da arte na língua portuguesa e suas literaturas, optou-se, como anteriormente referido, por dividir o campo dos estudos em três, a linguística, a literatura e a tradução, para orientar o processo de análise e facilitar a compreensão, por parte do leitor, da eminente diversidade da língua portuguesa e dos estudos sobre ela e com o intuito de apresentar de forma eficiente as pesquisas realizadas neste setor, em especial, para um leitor que não está familiarizado com tais estudos. 
O campo da linguística da língua portuguesa foca-se nas pesquisas sobre a fonética, a ortografia, a morfologia e a formação de palavras, a estrutura da língua e suas peculiaridades e o discurso em língua portuguesa e seus procedimentos de análise a partir da linguística textual e da pragmática da língua.

No campo da fonética-ortográfica encontramos várias modalidades de investigação nas diferentes regiões do mundo. Nessas pesquisas fonéticas salientam-se as de Maria Helena Mira Mateus em Portugal e Luiz Carlos Cagliari no Brasil. Mateus se dedica à fonética, à fonologia, à prosódia portuguesas, na modalidade do português de Portugal, usando a teoria gerativa de Noam Chomsky. A autora parte de princípios universais que regem a língua e que geram parâmetros linguísticos para analisar a relação de transformação entre esses princípios e os casos linguísticos específicos (MATEUS, 2016). Cagliari também estuda a fonética, a fonologia e a prosódia, porém com enfoque no português brasileiro, com uma metodologia descritiva a partir da teoria sistêmica funcional de Halliday. Cagliari explica como funciona a língua nos três aspectos ideacional, interpessoal e textual. 0 primeiro indica o propósito da fala, o segundo explica a relação do falante com seu interlocutor e o terceiro analisa a relação do texto com o contexto da fala (CAGLIARI, 2007).

Na morfologia e formação das palavras em língua portuguesa, temos que nos referir aos estudos clás- 
sicos de Joaquim Mattoso Câmara sobre a estrutura da língua portuguesa, às recentes pesquisas sobre as estruturas morfológicas do português de Luiz Carlos de Assis Rocha e às tendências atuais na formação de palavras de Carlos Alexandre Gonçalves (CÂMARA, 1986; ROCHA, 1998, GONÇALVES, 2016). No nível das gramáticas e sintaxe da língua portuguesa, temos as gramáticas de Duarte, Bechara e Cunha. Duarte elabora uma gramática textual em que associa o texto à análise gramatical, já Bechara e Cunha tem uma abordagem mais descritiva das estruturas gramaticais da língua (MATEUS et al., 2003; BECHARA, 2008, CUNHA, 2016). Por fim, vale apontar as pesquisas da Ana Maria Brito que corroboram com a concepção Chomskyana da língua e gramática (MATEUS et al, 2003).

No campo da análise do discurso há Eni Orlandi (2012) que estuda o discurso a partir dos conceitos de Michel Pêcheux (2011) e Beth Brait (2012a; 2012b) que cria o círculo de Bakhtin e a revista bakhtiniana para os estudos do discurso. No campo da linguística textual, podemos indicar as pesquisas de Koch que descreve os gêneros textuais nas diferentes situações comunicativas (KOCH, 2015). Na pragmática da língua, há José Luís Fiorin que aplica as teorias de interpretação, anunciação e argumentação de Ducrot e Benveniste na língua portuguesa (FIORIN, 2016) e na área de Português Língua Estrangeira, Isabel Margarida Duarte (2020) que trabalha com a aplicação das 
teorias do discurso e da pragmática no ensino de português como língua não materna na modalidade de Portugal e José Carlos P. de Almeida Filho (2005) na modalidade brasileira.

No campo das literaturas de língua portuguesa, os estudos abrem-se para várias formas discursivas. A análise da poesia e da prosa portuguesa, brasileira e africanas atravessa diferentes abordagens como a semiótica de Luiz Tatit (1995), a filosófica de Alfredo Bosi (2005), Luiz Costa Lima (2018) e Paulo Franchetti (2012), a analítica social de Antonio Candido (1987 e 1997), a histórica de Benjamin Abdala Jr. e Helena Buesco (2014) e a geopoética de Ida Alves (2013). Nos estudos das narrativas, apontamos para uma aproximação que considera essas formas como lugares da memória cultural nas leituras de Isabel Pires de Lima (1987), Carlos Reis (1995), Teresa Cristina Cerdeira Silva (1999), Regina Dalcastagnè (2018), entre outros. Nos estudos do drama, ressaltamos as pesquisas que analisam o teatro a partir da teoria do espetáculo de Guy Debord cuja abordagem ressalta o contexto histórico da elaboração da obra teatral, pensando na escrita genética da peça (MAGALDI, 2001).

No que se refere ao campo da tradução, partimos dos três processos de Williams e Chesterman (2002) que se configuram como os sentidos e os significados das palavras a serem traduzidas elaborados por meio do ato de ler, interpretar e compreender (STEINER, 1975), a recriação e reexpressão desses significados 
e, por fim, a publicação e recepção da obra (BAKER, 1998).

Nesse sentido, as pesquisas em língua portuguesa e suas literaturas destacam-se principalmente nos estudos linguísticos, literários e de tradução, com aplicabilidade nos mais diversos campos sociais. Os caminhos da pesquisa na língua portuguesa e suas literaturas serão trilhados, a partir da concepção da linguagem em três eixos: significar, comunicar e interagir (TRAVAGLIA, 1996).

\section{Significar}

Significar é o eixo da produção dos sentidos na interpretação dos discursos. Os conceitos de interdisciplinaridade epistêmica e comparatismo solidário são utilizados para discutir o objeto, bem como a relação de diálogo entre a história e a política na língua e suas literaturas. As pesquisas aplicadas na área ganham mais espaço político e social quando se cruzam com outras disciplinas por meio da interdisciplinaridade, multidisciplinaridade ou transdisciplinaridade e com um viés de comparação solidária. 
3.1. Interdisciplinaridade epistêmica e comparatismo solidário

A interdisciplinaridade epistêmica se refere ao método de análise que reflete sobre o encontro de duas disciplinas distintas quando elas se aproximam de um mesmo objeto de estudo com metodologias diferentes (BUNGE, 2000). 0 comparatismo solidário é oposto do competitivo, sendo este último um aglomerado de pesquisas que trabalham com o conceito hoje largamente ultrapassado das influências de uma obra, autor ou fenômeno em outros. Já o solidário, busca o estudo das relações entre as obras literárias em diálogo e interações de mútua cooperação. Como nessas obras, autores e fenômenos cooperam entre si, vão-se construindo propostas colaborativas para solucionar problemas ou propor questões em comum e desenvolver projetos e ideias de pesquisa com fins humanistas. Ao estudar um objeto da cultura humana como a língua e suas expressões, há duas dimensões a serem observadas, uma científica e epistemológica e outra social e cultural. Essa produção de conhecimento deve ser regida por uma ética, a da solidariedade. Nas discussões em torno desse princípio que rege nossos estudos está o diálogo das diferenças, uma "administração inteligente das diferenças" (ABDALA, 2017), para melhor resolução dos problemas epistemológicos e das crises da humanidade, tanto na 
literatura como na política ou tanto no pensamento como na expressão linguística.

Os estudos da língua portuguesa envolvem uma polifonia cultural de caráter pluricêntrico, por isso, surgem nos estudos da língua portuguesa e suas literaturas temáticas como identidades híbridas, interculturalidades, alteridades, entrelugares entre outras que caracterizam esse espaço marcado historicamente por amplas misturas culturais. Esses entrelugares definem-se como zonas intermediárias em contato (SANTIAGO, 1978). Essas misturas podem ainda ser estudadas na perspectiva histórica das Américas, como no projeto de Zilda Bernd, na UFRGS, ou na visão comunitarista cultural dos países falantes de português, estudados dentro da linha de pesquisa de Estudos Comparados da FFLCH/USP. Dessa ótica última, encontra-se Benjamin Abdala Jr. que acredita nas confluências culturais históricas entre os países da CPLP com fronteiras múltiplas nas Américas, Península Ibérica, África e Ásia.

Dentro desse projeto, há os trabalhos de Simone Caputo Gomes sobre Cabo Verde (GOMES, 2008) e as pesquisas de Rita Chaves sobre Angola (CHAVES, 1999). Em Portugal, as pesquisas de Ana Mafalda Leite acerca da literatura moçambicana (LEITE, 2004). Sobre Macau, na China, há os estudos da Fundação Oriente em Portugal e as pesquisas de Helder Garmes (2017) que também abordam Goa, na Índia, e sobre 
Timor-Leste, a tese de doutorado de Damares Barbosa (2013).

Seguindo Abdala (2007), a área da língua portuguesa e suas literaturas dialoga com outras disciplinas como a história, a geografia, a psicologia, a antropologia, a sociologia em abordagens epistemológicas multidisciplinares e interdisciplinares que se cruzam no nosso objeto de estudo e revitalizam a sua pesquisa e a sua aplicabilidade nos campos da tradução, da educação, do turismo e das relações internacionais.

\subsection{Língua Portuguesa e suas literaturas, história e política}

Nessa perspectiva relacional entre a história, a política e os estudos da língua portuguesa, surgem questões novas no que tange à expressão literária, como a problemática do fundamentalismo e do terrorismo e de suas raízes na crise econômica, social e cultural e o modo como isso interfere na literatura e na sua produção de conhecimento no século XXI (ABDALA, 2012).

Esse problema permeia os processos de interpretação multiperspectival e a produção dos discursos e dos imaginários sociais, especialmente o discurso do humor e sua relação com os aspectos políticos, sociais, culturais e linguísticos na esfera local e global (ELGEBALY, 2015). Nisso, explora-se ainda a relação entre as dinâmicas da expressão desses problemas 
culturais, especialmente a marginalização na literatura da periferia. E, nesse sentido, busca-se perceber estratégias discursivas de tradução cultural nas literaturas de língua portuguesa para traçar cada vez mais a distinção discursiva entre resistência e terrorismo nos estudos das literaturas da marginalidade. E, assim, temos cada vez mais grupos que se dedicam aos estudos das vozes literárias marginalizadas como a literatura regional do Amazonas, as africanas de língua portuguesa e os estudos do gênero, etc. A análise da escrita memorialística na marginalidade cruza-se com a condição humana, que engloba questões complexas como a ambiguidade das representações discursivas e a sua veracidade (RICOEUR, 2007).

\section{Comunicar}

Comunicar é o eixo da transmissão dos sentidos nas mais variadas situações culturais e sociais. Nas pesquisas sobre a língua portuguesa e suas literaturas, a comunicação acontece por meio da polifonia nas sociedades e em processos interculturais e, em alguma medida, tem a tradução como uma possibilidade de exteriorização dessas diversidades. 


\subsection{Língua Portuguesa e suas literaturas, sociedade, polifonia e interculturalidade}

O diálogo da área da língua portuguesa e suas literaturas com os estudos interculturais supõe que toda cultura é produto de misturas de diferentes tradições (PYM, 1998). Essa combinação gera interculturas, fruto das interações de alteridades internas e externas, gerando a noção de entrelugar (SANTIAGO, 1978). 0 conceito é desenvolvido por Santiago para se referir ao encontro das culturas indígenas e europeias e o processo de desenvolvimento de um não lugar, o entrelugar, fruto desse contato. Homi Bhabha, anos mais tarde, delineia um conceito semelhante, para se referir ao encontro das diferenças culturais e sua convivência num terceiro espaço que ele chama de inbetween, mas não necessariamente num processo de hibridação como adota Santiago (BHABHA, 2001). Aqui, a língua portuguesa será abordada a partir de suas pesquisas relacionadas a sua história e suas comunidades, em observância às questões sociais e à interculturalidade de seus falantes.

A língua portuguesa - como grande parte das chamadas línguas românicas - foi se desenvolvendo na Idade Média a partir do cruzamento com outras línguas e culturas, como o árabe e o espanhol, este último, também em processo de formação. Ressaltamos, a princípio, as culturas árabes e sua contribuição na construção dessa língua e suas literaturas, inicialmen- 
te durante a presença árabe na península ibérica no medievo e, posteriormente, no contato dos imigrantes árabes no Brasil e em Portugal. Esta é uma área de pesquisa fértil para novas descobertas nos estudos das memórias interculturais. Em seguida, trataremos da relação da língua portuguesa com a espanhola, que se constituíam após o desmembramento do Império Romano do Ocidente e se consolidaram nas Idades Média e Moderna (TEYSSIER, 1982). É importante ressaltar que Real (2001) estabelece como uma característica das culturas lusófonas a espera por um salvador nos momentos de crise, aspecto também presente entre os espanhóis e árabes na figura dos homens fortes da política.

As heranças árabes na língua portuguesa se apresentam também nas traduções das obras que proporcionaram o amadurecimento do humanismo renascentista português. Essas ressonâncias são bem visíveis nos topônimos portugueses, mas também aparecem nos conhecimentos geográficos e nas ciências do mar, saberes que serviram no desenvolvimento do conhecimento necessário para a realização das navegações (ADALBERTO, 1999).

Outra questão a ser pesquisada é esse cruzamento entre as culturas de língua portuguesa e as africanas-árabes, denominada Afrabia, - países africanos falantes de língua árabe (MAZRUI, 1992). Os contatos interculturais durante a escravidão, quando muitos indivíduos da Afrabia foram escravizados, levados 
a força para as Américas e tiveram que se adaptar à nova língua, deixou marcas no desenvolvimento linguístico e cultural da Língua Portuguesa e suas literaturas. A saber, temos o campo das literaturas afro-brasileiras com Conceição Evaristo que cria o conceito de "escrevivência" que traz para a escrita a experiência de vida das mulheres negras na realidade brasileira (EVARISTO, 2008).

Ao mencionar a Espanha, também houve um diálogo genético e histórico entre a língua espanhola e a portuguesa (CUNHA, 2016), tanto pela proximidade geográfica como pelo período da União Ibérica (RAMOS, 2009). Por isso, as pesquisas da língua portuguesa e suas literaturas encontram-se frequentemente com o problema da interferência da língua espanhola, uma questão que pode ser analisada para propor soluções para a aprendizagem e a comunicação nessas línguas irmãs sem interferências (FANJUL E GONZÁLEZ, 2014).

Tais misturas levam à reflexão sobre a relação comparatista entre a língua portuguesa e suas literaturas e a sociedade. Ressaltam as questões associadas à crise do positivismo e do sistema social patriarcal desde os finais do século XIX, discussões elaboradas por meio da análise das representações sócio-políticas das mulheres nas literaturas e na imprensa de língua portuguesa (BERRINI, 1982; COELHO, 2002; ELGEBALY, 2017b; ELGEBALY, 2018a). 


\subsection{Língua portuguesa e suas literaturas e a tradução}

A tradução é uma das formas de comunicar a língua, suas culturas e literaturas. Adotamos o conceito de Boaventura Santos, a tradução é "um trabalho argumentativo de imaginação epistemológica e de imaginação democrática presente nas reflexões e preocupações de todas aquelas perspectivas, movimentos e práticas que propõe o objetivo de construir novas e plurais formas de emancipação social" (SANTOS, 2005, p. 168).

No Brasil, hoje destacam-se os grupos de pesquisa sobre a tradução na Universidade Federal de Santa Catarina e na Universidade de São Paulo e outros mais recentes nas universidades federais do Nordeste.

Dentro das três abordagens da tradução de Williams e Chesterman (2002), encontra-se na primeira a hermenêutica do tradutor, o que dignifica dizer os processos de compreensão e interpretação na tradução. Já no século XIX, o padre Schleimacher (2004) questionava a importância de o tradutor conservar as expressões originais do texto ou domesticar o texto para a cultura receptora. George Steiner (1975) dividia a tradução na decodificação do texto original, na familiarização com o texto e na reexpressão, quando o tradutor começa a pensar quais expressões e palavras vai usar na língua receptora para a melhor compreensão da obra traduzida. 
Na segunda, há a retórica da tradução, os processos de transferência e reescrita da tradução na língua-alvo, aqueles que buscam um ponto de equilíbrio entre a tradução livre e a literal. Entre a estrangeirização e a domesticação existe uma zona intermediária que é a "tradução da letra". Nessas reescritas, é interessante buscar as estratégicas e técnicas da tradução (BARBOSA, 1990; BERMAN, 2013).

Na terceira, analisa-se a recepção da tradução no mercado editorial e a relação dos leitores com o próprio texto. Os pesquisadores dessa área lidam com a tradução segundo os pressupostos de Pierre Bourdieu (GOUANVIC, 2005). Uma das abordagens trata a tradução como uma mercadoria, preocupando-se com os tipos de leitores e os possíveis usuários dessas obras, outra trata de uma aproximação polissistêmica, que estuda os múltiplos sistemas de relações e funções envolvidas na tradução (ABDALA, 2001).

Paul Ricoeur discute a "traduzibilidade" dos textos e os desafios de traduzir algumas obras. Ele analisa o grau da significação entre uma língua e outra e os problemas da tradução. Eles dependem do tema e de seus aspectos linguísticos, sintáticos e léxicos, e extralinguísticos, idiossincráticos e de realidades distintas, da situação comunicativa e da perspectiva espacial com suas duas dimensões, a cultural e a natural (RICOEUR, 2011; ELGEBALY, 2012).

Finalmente, percebe-se que a tradução ganha uma dimensão especial no contexto dos estudos intercul- 
turais, como uma comunicação e intermediação de culturas e como transferência de uma experiência de um lugar para outro. Nesse sentido, os estudos da tradução abrem-se a um leque amplo de possibilidades que se preocupam com o encontro perene das alteridades durante intervenções do tradutor e suas marcas na interpretação e comunicação entre as culturas.

\section{Interagir}

0 eixo que corresponde ao interagir é a terceira função da língua, aquela que gera ações. A interação se refere à relação entre os usuários da língua e a uma ação na realidade. Por exemplo, o uso do imperativo nas línguas proporciona uma interação entre a fala e a realidade.

\subsection{Interação entre língua Portuguesa e suas} literaturas, a viagem e o turismo

O turismo associa-se a uma tradição da literatura portuguesa que relaciona o texto literário à viagem e ao turismo tais como $O$ turista aprendiz, de Mário de Andrade (1976), Viagem a Portugal, de José Saramago (1981) e As crônicas de viagem, de Cecília Meirelles (1999). Percebe-se uma relação de fruição e aprendizagem entre o turista e os lugares percorridos. E a viagem aparece nessas literaturas como uma experiência humana no diálogo entre as culturas e uma re- 
lação com lugares, pessoas e tempos. E o que protagoniza uma literatura de viagem é, principalmente, a estética das relações, considerando que a viagem deixa transparecer a posição do viajante no entrelugar.

$\mathrm{E}$ ao associarmos a viagem, o turismo e a língua e suas literaturas criamos uma interação rica em possibilidades de pesquisas e produção de conhecimento que impactam, especialmente, o turismo cultural e colocam em prática a interdisciplinaridade entre a história e a literatura por meio da escrita memorialística das viagens. Essa escrita levanta questões como a relação afetiva entre o viajante e o lugar, assim como a “escrita de si" (FOUCAULT, 1983) na percepção desse lugar. É possível analisar o imaginário do local durante a viagem por meio da técnica da "escrita de si" desse viajante, em interface com análises quantitativas e qualitativas do conteúdo da imprensa local no período da viagem. Assim, pode-se comparar a experiência dos viajantes nas narrativas de viagens entre as duas regiões (ELGEBALY E PINTO, 2019). Essa análise abre possiblidades de revelar o impacto dessas viagens na formação dessa escrita memorialística em língua portuguesa (ELGEBALY, 2020), marcada miticamente pelo livro fundador Os Lusíadas (CAMÕES, 2002).

Outro aspecto dessa interação é a releitura de locais literários ficcionais na realidade pelos circuitos turísticos, como nos itinerários de Eça de Queiroz em Portugal, os do Grande Sertão Veredas, de Guimarães 
Rosa, e a Vila Rica de Tomas Antônio Gonzaga e Cláudio Manuel da Costa.

\subsection{Interação entre a língua portuguesa e suas literaturas e a educação}

A interseção entre a língua portuguesa e suas literaturas e a educação se dedica a estudar as variadas experiências e contribuições no seu ensino (ELGEBALY, 2018b). Essas temáticas podem ser divididas em vários grupos, porém vamos ressaltar a alfabetização, o letramento, o multiletramento, o ensino de literatura e a literatura infanto-juvenil e, por fim, o ensino de português como língua estrangeira.

Sobre a alfabetização, temos principalmente a professora Magda Soares (2017) que faz uma compilação entre os métodos psicolinguísticos de Piaget e pedagógicos de Paulo Freire aplicados na alfabetização em língua portuguesa. A autora utiliza também a abordagem semiótica do grupo de pesquisa de multiletramento, New London Group, da Universidade de Harvard para a aprendizagem da língua.

Em relação aos trabalhos de letramento temos Gee (2015) que analisa a alfabetização, a leitura e a escrita nos diferentes gêneros discursivos. Ultimamente, fala-se do multiletramento, diferentes modos de circulação da linguagem, dentro dos estudos de letramento em referência à interseção de muitas culturas na leitura e na escrita. Ainda nessa linha, há 
os grupos de pesquisa da leitura e do letramento na Faculdade de Educação da Universidade de São Paulo, na Faculdade de Educação da Universidade Federal de Minas Gerais e em universidades do norte e do nordeste do Brasil (SOARES, 2017).

No ensino da língua portuguesa e suas literaturas, distinguem-se as pesquisas desenvolvidas pela professora Nelly Coelho (1991) da USP sobre a literatura infanto-juvenil. A autora estuda a literatura associando-a ao contexto histórico, numa contraposição entre sincronia e diacronia.

No ensino da língua portuguesa e suas literaturas aprecia-se cada vez mais o ensino das variações linguísticas e literárias, a partir de uma metodologia que permita fazer dialogar a história social da língua e suas literaturas, à geopolítica e à economia (ELGEBALY et al, 2017a). Nesse campo podemos referir-nos às pesquisas do Instituto dos Estudos da Linguagem da Unicamp e as universidades do norte do Brasil sobre o multiletramento e a formação de leitores (COSSON, 2020).

0 ensino de português como língua adicional no Egito passa por dois caminhos, o da fruição do prazer no contato com culturas distintas e o da mudança de uma mentalidade monossêmica para a polissêmica. No primeiro caminho, temos o contato dos estudantes com elementos culturais dos países da CPLP, no segundo, acontece uma passagem de uma mentalidade que atribui um sentido único a cada forma linguís- 
tica e vice-versa, para começar a pensar polissemicamente e expressar os sentidos linguísticos e culturais de várias maneiras. Tanto a fruição como a interculturalidade conduzem a uma profissionalização positiva na língua e na cultura.

Esse campo de pesquisa que associa a educação à língua e suas literaturas, para nativos e não-nativos, crianças e adultos, perpassa as questões interculturais dos grupos falantes e daqueles alvo da aprendizagem, numa perspectiva de diálogo entres os saberes do aprendiz e do professor, inseridas nos processos de pesquisa da alfabetização, multiletramento, os estudos sobre ensino de literatura e literatura infantil e o ensino de português como língua adicional (PLE).

\section{Considerações finais}

Tentamos traçar possíveis caminhos na pesquisa em língua portuguesa e suas literaturas, o que engloba diversas subáreas. Foi feito um recorte para elaborar essa revisão que atravessa diferentes culturas e disciplinas e que passa, certamente, por nossa própria experiência, fato que nos orientou na seleção das pesquisas. Partimos nesse recorte dos sentidos da prática linguística, literária, tradutória e educativa da linguagem humana: significar, comunicar e interagir.

Em primeira instância, a complexidade dessas experiências em língua portuguesa ganha sentido por meio da interdisciplinaridade e da cooperação na 
busca humana por novas descobertas. Esse olhar sobre a língua portuguesa e suas literaturas emana das situações e dos contextos históricos e sociopolíticos da sua produção e recepção. Em segunda instância, esses conhecimentos em língua portuguesa se comunicam entre culturas por meio da intermediação e tradução intercultural. E em terceira instância, elas interagem com outras áreas como o turismo e a educação, colocando-se a serviço de outras atividades como ferramenta para a atuação desses profissionais.

É preciso que a pesquisa esteja sensível às novidades da linguagem contemporânea, especialmente à mistura de experiências nas novas discursividades literárias emergentes das novas tecnologias de informação e de comunicação. Isso coloca a classificação tradicional dos gêneros literários em crise e permite a emergência de novas formas linguísticas e literárias. (REIS, 1996). 


\section{Referências}

ABDALA Jr, B. Terra morta e outras terras: sistemas literários nacionais e o macrossistema literário da língua portuguesa. Veredas. Revista da Associação Internacional de Lusitanistas, Porto, v. 3, n.II, p. 523-536, 2001.

ABDALA Jr, B. Literatura, história e política - $2^{\mathrm{a}}$ edição. $2^{\mathrm{a}}$. ed. Cotia: Ateliê Editorial, 2007.

ABDALA Jr., B. Fronteiras (múltiplas), identidades (plurais), comunitarismos (culturais). Revista Olho d'água, v. 4(2), p. 30-40, 2012.

ABDALA Jr, B. Estudos comparados: teoria, crítica e metodologia. 1. ed. Cotia (SP): Ateliê Editorial, v. 1, 2014.

ABDALA Jr, B. Reflexões comunitárias e administração de diferenças. SIGNOTICA (UFG), v. 29, p. 15-26, 2017.

ADALBERTO, José Coelho Alves. Portugal: ecos de um passado árabe. Lisboa: Colecção Lazúli, Instituto Camões, 1999.

ALMEIDA FILHO, José Carlos Paes. Linguística aplicada, ensino de línguas e comunicação. Campinas: Pontes Editores / ArteLíngua, 2005.

ALVES, Ida. Em torno da paisagem: literatura e geografia em diálogo interdisciplinar. Revista da ANPOLL (Online), v. 1, p. 181, 2013. Disponível em: https://anpoll.emnuvens. com.br/revista/article/view/650.

ANDRADE, Mário de. O Turista Aprendiz. Estabelecimento do texto, introdução e notas de Telê Porto Ancona Lopez. São Paulo: Duas Cidades/Secretaria de Cultura, Esportes e Tecnologia, 1976.

BAKER, Mona. Encyclopedia of Translation Studies, London: Routledge, 1998.

BARBOSA, Damares. Roteiro da Literatura de Timor-Leste em Língua Portuguesa. (2013) Tese (Doutorado) - Faculdade de Filosofia e Ciências Humanas da Universidade de São Paulo, São Paulo, 2013. 
BARBOSA, Heloisa Gonçalves. Procedimentos técnicos da tradução, uma nova proposta. 1. ed. Campinas: Pontes Editores, v. 1, 1990.

BECHARA, Evanildo. Moderna Gramática Portuguesa. 37ạ ed. rev. e amp. Rio de Janeiro: Editora Lucerna e Editora Nova Fronteira, 2009.

BERMAN, Antoine. Tradução e a Letra ou O albergue do longínquo. Florianópolis: Tubarão, 2013.

BERND, Zilá. Dicionário de figuras e mitos literários das americas. Porto Alegre: Editora da Universidade/UFRGS e Tomo Editorial, v. 01, $2007 .$.

BERRINI, Beatriz. Presença feminina em Eça de Queiroz. Boletim Bibliográfico Biblioteca Mário de Andrade, São Paulo, v. 43, n.3 e 4, p. 81-86, 1982.

BHABHA, Homi K. O local da cultura. Belo Horizonte: Editora UFMG, 2001.

BOSI, Alfredo. Caminhos entre a literatura e a história. Estudos Avançados (USP. Impresso), v. 19, p. 315-334, 2005. BRAIT, Beth. Bakhtin: conceitos-chave. 5. ed. São Paulo: Contexto, v. 1, 2012a.

BRAIT, Beth. Bakhtin: outros conceitos-chave. 2. ed. São Paulo: Contexto, v. 1, 2012b.

BUESCU, Helena Carvalhão. Inventar a Ler. Literatura-Mundo em Português. In: ABDALA Jr., B. Estudos comparados: teoria, crítica e metodologia. 1. ed. Cotia (SP): Ateliê Editorial, 2014.

BUNGE, Mario. La investigación científica. Su estrategia y su filosofía. México: Siglo XXI Editores, 2000.

CAGLIARI, Luiz Carlos. Elementos de Fonética do Português Brasileiro. 1. ed. São Paulo: Paulistana, v. 1, 2007.

CÂMARA, Joaquim Mattoso. Estrutura da língua portuguesa. 16 ed. Petrópolis: Vozes, 1986.

CAMÕES, Luís de. Os Lusíadas. 1.a ed. Lisboa: Rei dos Livros, 2002.

CANDIDO, Antonio. O estudo analítico do poema. Humanitas Publicações. São Paulo: 1987. 
CANDIDO, Antonio. Iniciação à literatura brasileira. São Paulo: Humanitas Publicações, 1997.

CHAVES, Rita. A formação do romance angolano: entre intenções e gestos. Coleção Via Atlântica, $n^{\circ} 1$. São Paulo, 1999.

COELHO, Nelly Novaes. Panorama histórico da literatura infantil/juvenil. São Paulo: Ática, 1991.

COELHO, Nelly Novaes. Dicionário crítico de escritoras brasileiras, 1711-2002. São Paulo: Escrituras, 2002.

COSSON, Rildo. Paradigmas do ensino da literatura. São Paulo: Contexto, 2020.

COSTA LIMA, Luiz. Poesia e experiência estética. REVISTA DE TEORIA DA HISTÓRIA, v. 20, p. 29-40, 2018.

CUNHA, Celso Ferreira da; CINTRA, Luís Filipe Lindley. Nova gramática do português contemporâneo. Rio de Janeiro: Editora Lexikon, Edição 7, 2016.

DALCASTAGNÈ, Regina. A crítica literária em periódicos brasileiros contemporâneos: uma aproximação inicial. ESTUDOS DE LITERATURA BRASILEIRA CONTEMPORÂNEA, v. 54, p. 195-209, 2018.

DUARTE, Isabel Margarida; e LEÓN, Rogelio Ponce de. Marcadores discursivos: 0 português como referência contrastiva. Frankfurt: Peter-lang, 2020.

ELGEBALY, Maged Talaat Mohamed Ahmed. Mobilidades culturais e alteridades em Relato de um certo oriente e sua pré-tradução árabe. 2012. Tese (Doutorado em Estudos Comparados de Literaturas de Língua Portuguesa) - Faculdade de Filosofia, Letras e Ciências Humanas, Universidade de São Paulo, São Paulo, 2012.

ELGEBALY, Maged T. M. A. Raízes do Terror". MALALA - REVISTA DO GRUPO DE TRABALHO ORIENTE MÉDIO E MUNDO MUÇULMANO (GTOMMM) da FFLCH, USP, v. 3, p. 153, 2015. ELGEBALY, Maged T. M. A.; RODRIGUES SILVA, WAGNER; DE MEDEIROS, ANA LÚCIA. Pelo ensino do português brasileiro como língua adicional no Egito. Revista Gragoatá (UFF), v. 22, p. 473-498, 2017a. 
ELGEBALY, Maged T. M. A. Mulheres como cenário de crítica social: Luísa de 0 primo Basílio e Rita de A cartomante. In: I Congresso Internacional de Letras (Língua Portuguesa e suas literaturas no mundo), de 23 ao 25 de agosto de 2017. UFMA, Bacabal, publicado em Carlos, SP pelos Pedro e João Editores, p. 1294-1304, 2017b.

ELGEBALY, Maged T. M. A. Entre imprensa e literatura: Luísa de 0 Primo Basílio e as mulheres em "Cinco mulheres" e "Missa do Galo" de Machado de Assis. In: IV COLÓQUIO INTERNACIONAL DE LITERATURA E GÊNERO, de 5 a 7 de setembro 2018a, FUESPI, TERESINA, PIAUÍ, v. 01, p. 162-173. ELGEBALY, Maged T. M. A. Travessias e desafios da introdução dos estudos da língua portuguesa no Egito. In: Práticas de ensino e tecnologias digitais. Campina Grande-PB: Editora da Universidade Estadual da Paraíba EDUEPB, p. 499-517, 2018b.

ELGEBALY, Maged Talaat Mohamed Ahmed; PINTO, Liliane Faria Correa. 0 Egito na interface entre o diário de Dom Pedro II e os jornais "Diário de Maranhão" e "Diário do Rio de Janeiro" em 1876 e 1877. Via Atlântica, v. 35, p. 333, 13 DE NOVEMBRO, 2019.

ELGEBALY, Maged Talaat Mohamed Ahmed. Travessias de Eça de Queiroz entre a inauguração do canal de Suez e o começo literário. Revista Anthesis. UFAC, Rio Branco (Acre, Brasil). ISSN 2317-0824, 30 de junho 2020.

EVARISTO, Conceição. Escrevivências da Afro-Brasilidade: história e memória. Releitura (Belo Horizonte), v. 1, p. 5-11, 2008.

FANJUL, Adrian Pablo; GONZÁLEZ, Neide Therezinha Maia (Org.). Espanhol e português brasileiro: estudos comparados. São Paulo: Parábola Editorial, v. 1, 2014.

FIORIN, José Luiz. As astúcias da enunciação. As categorias de pessoa, espaço e tempo. 3. ed. São Paulo: Contexto, v. 1, 2016.

FOUCAULT, Michel. A escrita de si. Corps écrit, no. 5: L'autoportrait, p. 3-23, 1983. 
FRANCHETTI, Paulo. Alguns aspectos da teoria da poesia concreta. 4. ed. Campinas: Editora da Unicamp, v. 1, 2012. GARMES, Helder. Goa e Macau: às margens do macrossistema literário de língua portuguesa. In: Monica Simas. (Org.). Estudos sobre Macau e outros Orientes. 1ed. São Paulo: Editora Paulistana, v. 1, p. 169-183, 2017.

GEE, James Paul. Literacy and education. New York: Routledge, 2015.

GOMES, Simone Caputo. Cabo Verde: Literatura em chão de cultura. 1. ed. Cotia-Praia (Cabo Verde): Ateliê Editorial e Instituto da Biblioteca Nacional e do Livro, v. 1, 2008.

GONÇALVES, Carlos Alexandre Victorio. Atuais tendências em formação de palavras. São Paulo: Contexto, 2016. v. 1.

GOUANVIC, Jean-Marc. A Bourdieusian Theory of Translation, or the Coincidence of Practical Instances. Field, "Habitus", Capital and "Illusio". In: INGHILLERI, M. (Ed.) Bourdieu and the Sociology of Translation and Interpreting. The Translator, Special Issue. Manchester, UK: St. Jerome, 2005. p. 147-166.

KOCH, Ingedore Grünfeld Villaça. Introdução a linguística textual. São Paulo: Editora Contexto, 2015.

LEITE, A. M. M. Literaturas Africanas e Formulações Pós-Coloniais. Maputo: Imprensa Universitária, 2004.

LIMA, Isabel Pires de. As máscaras do desengano: Para uma abordagem sociológica de "Os Maias" de Eça de Queirós. Lisboa: Editorial Caminho, 1987.

MAGALDI, Sábato Antônio. Panorama do Teatro Brasileiro. Rio de Janeiro: Global Editora, 2001.

MATEUS, Maria Helena Mira; BRITO, Ana Maria; DUARTE, Inês; FARIA, Isabel Hub. Gramática da língua portuguesa. Lisboa: Editorial Caminho, 2003.

MATEUS, Maria Helena Mira; FALÉ, Isabel; FREITAS, Maria João. Fonética e fonologia do português. Lisboa: Universidade Aberta, 2016.

MAZRUI, Ali A. Africa: africa and arabs in new world order. UFAHAMU. University of California, Los Angeles, 1992. 
MEIRELES, Cecília. Crônicas de viagem. Volumes (1), (2) e (3). (Obra em prosa). Rio de Janeiro: Nova Fronteira, 1999. ORLANDI, Eni Puccinelli. Análise de Discurso princípios e procedimentos. 5a ed. Campinas, SP: Pontes Editores, 2003. PALUMBO, Giuseppe. Key terms in translation studies. Chennai: Editorial Continuum, 2009

PECHEUX, Michel. Análise do Discurso, textos escolhidos $e$ traduzidos por Eni Puccinelli Orlandi. Campinas, Campinas: Pontes Editores, 2011.

PYM, Anthony. Method in Translation History. London/ Manchester: St Jerome Eds, 1998.

REAL, Miguel. Introdução a cultura portuguesa: séculos XIII a XIX. Lisboa: Planeta, 2001.

REIS, Carlos. $O$ conhecimento da literatura: introdução aos estudos literários. Livraria Almedina, 1995.

RICOEUR, Paul. A memória, a história, o esquecimento. Tradução de Alain François. Campinas, SP: Editora da UNICAMP, 2007.

RICOEUR, Paul. Sobre a tradução. Tradução e prefácio de Patrícia Lavelle. Belo Horizonte: Editora UFMG, 2011.

ROCHA, Luiz Carlos de Assis. Estruturas morfológicas do Português. 1. ed. Belo Horizonte: Editora UFMG, v. 1, 1998. SANTIAGO, Silviano. 0 entrelugar do discurso latinoamericano. In: Uma literatura nos trópicos: ensaios sobre depenência cultural. São Paulo: Perspectiva. Secretaria da Cultura, Ciência e Tecnologia, 1978.

SANTOS, Boaventura de Sousa. El milenio huerfáno. Madrid: Akal, 2005

SARAMAGO, José. Viagem a Portugal. Lisboa: Círculo do Livro, 1981

SCHLEIERMACHER, Friedrich. On the Different Methods of Translating. In: VENUTI, Lawrence (ed.). The Translation Studies Reader. New York: Routledge, 2004.

SILVA, Teresa Cerdeira Cristina. Do labirinto textual ou da escrita como lugar de memória. Revista Colóquio/Letras, Lisboa - Portugal, v. 151/2, p. 249-266, 1999. 
SOARES, Magda. Alfabetização: a questão dos métodos. São Paulo: Contexto, 2017.

STEINER, George. After Babel. Oxford: Oxford University Press, 1975.

TAILCHE, Khalid. Memória cultural e alteridades na diáspora árabe nas Américas: liga Andaluza em São Paulo e a Associação do Cálamo em Nova Iorque. (Trabalho de Pós-doutorado). São Paulo: FAPESP. FFLCH - USP, 2015

TATIT, Luís. Semiótica da canção: música e letra. São Paulo: Escuta, 1995.

TEYSSIER, Paul. História da língua portuguesa. Tradução de Celso Cunha. Lisboa: Sá da Costa, 1982.

TRAVAGLIA, Luiz Carlos. Gramática e interação - Uma proposta para o ensino de gramática no 1o. e 2o. graus. 1a.. ed. São Paulo: Cortez, 1996. v. 1.

WILLIAMS, Jenny \& CHESTERMAN, Andrew. The Map: A beginner's guide to doing research in translation studies. Manchester: St Jerome Publishing, 2002. 